\title{
Laurence Cadet, De Proust à Simon: le miroitement des textes
}

\section{Susanna Bonomi}

\section{Q OpenEdition}

1 Journals

\section{Edizione digitale}

URL: http://journals.openedition.org/studifrancesi/3864

DOI: $10.4000 /$ studifrancesi.3864

ISSN: 2421-5856

\section{Editore}

Rosenberg \& Sellier

\section{Edizione cartacea}

Data di pubblicazione: 1 décembre 2012

Paginazione: 611

ISSN: 0039-2944

\section{Notizia bibliografica digitale}

Susanna Bonomi, «Laurence Cadet, De Proust à Simon: le miroitement des textes», Studi Francesi

[Online], 168 (LVI | III) | 2012, online dal 30 novembre 2015, consultato il 07 mars 2021. URL: http:// journals.openedition.org/studifrancesi/3864 ; DOI: https://doi.org/10.4000/studifrancesi.3864

Questo documento è stato generato automaticamente il 7 mars 2021.

\section{(c) (i) $\odot$}

Studi Francesi è distribuita con Licenza Creative Commons Attribuzione - Non commerciale - Non opere derivate 4.0 Internazionale. 


\title{
Laurence Cadet, De Proust à Simon: le miroitement des textes
}

\author{
Susanna Bonomi
}

\section{NOTIZIA}

LAURENCE CADET, De Proust à Simon: le miroitement des textes, Paris, Champion, 2011

(«Recherches prous-tiennes»), pp. 347.

1 Il lavoro di Laurence Cadet si fonda su un preciso asserto: Proust, e in particolare la Recherche, sono un punto di riferimento per Claude Simon, tanto che la Recherche può essere usata per illuminare l'opera dello scrittore di Tananarive.

2 Prendendo le distanze dai lavori scritti in precedenza sul rapporto tra i due, Laurence Cadet analizza l'evolvere della filiation, come lei la definisce, da Proust a simon, distinguendo nell'avventura letteraria di quest'ultimo tre momenti, cui corrispondono le tre parti del testo.

3 La prima parte è dedicata all'analisi delle opere che Simon ha scritto tra il 1945 e il 1967. Per il novello scrittore, Proust è un modello, in quanto egli condivide la sua concezione dell'arte. I romanzi di Simon, in quel periodo, pongono al centro «l'ordre sensible des choses»: tutto si basa sulle sensazioni. Risulta allora fondamentale l'esperienza della malattia, che Proust ben conosceva, e soprattutto il ricordo involontario, scoperta tutta proustiana, che nelle opere di entrambi gli autori provoca uno sconvolgimento dell'ordine cronologico del racconto. Inoltre Simon riconosce a Proust la "paternità" della descrizione "dinamica", su cui si fonda il nuovo romanzo descrittivo.

4 Alle opere di Simon degli anni dal 1966 al 1975, l'epoca del tecnicismo letterario, è dedicata la seconda parte. Proust entra allora nell'opera di Simon a tutto tondo: intertesti, paratesti e perfino ipertesti. Tuttavia, Simon modifica le parole del "padre", inserendole nella sua opera frammentate e mutilate, private del loro contesto, usate come puro materiale scrittorio. La filiation, in questa fase, procede anche da una 
medesima concezione della lingua, fondamentalmente metaforica e ricca di materia sonora.

Il terzo periodo, 1981-2001, è per Simon quello del ritorno alla scrittura del vissuto. Il rapporto tra i due autori si modifica ancora: Simon usa Proust per giustificare le proprie scelte, l'intertesto è utilizzato come metatesto. La scrittura del vissuto reale reintegra il soggetto lirico che, come in Proust, è un soggetto plurale. Un altro punto di contatto tra i due scrittori è rappresentato dall'uso del racconto ermeneutico: per entrambi la storia è un enigma da risolvere. La presenza di numerose serie iterative nei testi di Simon di questo periodo, frequenti anche nella Recherche, fa saltare definitivamente l'ordine cronologico del racconto. In Le Jardin des plantes la Recherche assume una funzione metatestuale: Simon la cita fedelmente nel suo testo e la commenta; non solo, negli ultimi anni di scrittura il rapporto di filiation si modifica a tal punto che Proust diventa una proiezione personale di Simon. Grazie ad un'analisi puntuale, ricca di esempi presi dai testi, Laurence Cadet offre la possibilità di capire meglio le modalità della trasmissione letteraria da un autore ad un altro. 